06

\title{
Влияние рассеяния распыленных атомов на скорость роста пленок, полученных методом магнетронного распыления
}

\author{
(ㄱ Д.М. Митин, А.А. Сердобинцев
}

Саратовский национальный исследовательский государственный университет им. Н.Г. Чернышевского

E-mail: mitindm@mail.ru

\section{Поступило в Редакцию 31 марта 2017 г.}

Приведены результаты теоретических расчетов доли нерассеянных распыленных атомов при магнетронном распылении. Экспериментально полученная зависимость скорости роста пленок кремния от давления обнаруживает корреляцию с теоретически рассчитанной зависимостью доли нерассеянных распыленных атомов. Увеличение давления в рассматриваемом диапазоне $1.5-8.5 \mathrm{mTorr}$ приводит к снижению скорости роста пленок кремния на 25\%, при этом уменьшение доли нерассеянных распыленных атомов на расстоянии катод-подложка достигает $90 \%$.

DOI: 10.21883/PJTF.2017.17.44950.16804

В последнее время магнетронное распыление стало одним из основных методов создания тонких пленок, которые находят широкое применение в электронике, оптике, машиностроении и других технических областях.

Повышение производительности магнетронных распылительных систем (МРС) для промышленных нужд является одной из актуальных задач современной технической физики. Как правило, производительность МРС определяется мощностью разряда плазмы [1], величиной магнитного поля [2], глубиной зоны эрозии катода [3], а также другими технологическими параметрами и особенностями конструкции. Кроме того, одним из факторов, влияющих на производительность, является давление рабочего газа. Величина давления не только определяет чистоту и качество получаемых пленок, но и служит важнейшей характеристикой, от которой зависит процесс транспорта распыленных атомов [4]. Настоящая работа посвящена теоретическому и экспериментальному 
изучению влияния рассеяния распыленных атомов на скорость роста тонких пленок.

Чтобы учесть влияние давления рабочего газа в камере на количество распыленных атомов, запишем следующее выражение

$$
N_{s}=N_{p} K\left(E_{0}\right),
$$

где $N_{s}$ - количество распыленных атомов в секунду (скорость распыления), $N_{p}$ - количество первичных (бомбардирующих) ионов в единицу времени, $K\left(E_{0}\right)$ - коэффициент распыления материала катода, зависящий от энергии ионов рабочего газа. Величина $K\left(E_{0}\right)$ численно равна отношению количества первичных ионов, бомбардирующих катод, к количеству атомов, выбитых из катода в результате бомбардировки, и характеризует эффективность процесса распыления. В рассматриваемом диапазоне энергий бомбардирующих ионов (как правило, для MPC, работающих на постоянном токе, энергия составляет не более $1000 \mathrm{eV}$ ) коэффициент распыления изменяется пропорционально их энергии.

Известно, что энергия ионов рабочего газа однозначно связана с напряжением магнетронного разряда, зависящим в свою очередь от давления. Таким образом, коэффициент и скорость распыления также оказываются зависящими от давления в рабочей камере. Для определения количества первичных ионов $N_{p}$, попадающих на поверхность катода в секунду, воспользуемся тем фактом, что в процессе токопереноса в прикатодной области магнетронного разряда участвуют только ионы [5], т. е. данная величина пропорциональна току магнетронного разряда:

$$
N_{p}=\frac{I}{e},
$$

где $I$ - ток магнетронного разряда, $e-$ заряд электрона.

Для достоверного описания транспорта распыленных атомов необходимо учесть их рассеяние на атомах рабочего газа и распределение по длинам свободного пробега. Кроме того, простая оценка, основанная на модели упругих соударений, показывает, что при сравнимых массах атомов рабочего газа и катода распыленный атом теряет в таком соударении бо́льшую часть своей энергии. Очевидно, что определяющий вклад в переносимую на поверхность подложки энергию вносят атомы, не испытавшие соударений. Именно такие атомы рассмотрены в настоящей работе.

Письма в ЖТФ, 2017, том 43, вып. 17 
Воспользуемся известным из статистической физики соотношением для оценки доли испытавших соударения атомов при заданных значениях средней длины свободного пробега и расстояния катод-подложка. Вероятность события $C(L)$, состоящего в том, что длина свободного пробега атома не превышает расстояние катод-подложка, определяется выражением [6]:

$$
C(L)=1-\exp \left(-\frac{L}{\lambda}\right)
$$

где $L-$ расстояние катод-подложка, $\lambda-$ средняя длина свободного пробега, рассчитанная для каждого давления по формуле

$$
\lambda=\frac{k_{\mathrm{B}} T}{\sqrt{2} P_{g} \sigma},
$$

где $P_{g}$ - суммарное давление, создаваемое распыленными атомами и атомами рабочего газа, $k_{\mathrm{B}}$ - постоянная Больцмана, $T-$ температура, $\sigma$ - общее поперечное сечение, учитывающее сечения взаимодействий и обмен импульсами между сталкивающимися частицами, процессы возбуждения и ионизации.

Величина $\sigma$ имеет размерность площади и характеризует вероятность соударения частиц. Поперечное сечение является функцией энергии взаимодействующих частиц и в общем случае изменяется обратно пропорционально энергии. Выбранное значение $\sigma$ соответствует максимуму распределения Зигмунда-Томпсона [7], которое описывает начальный энергетический спектр распыленных атомов. Величина максимума распределения Зигмунда-Томпсона соответствует энергии, с которой покидает мишень большинство распыленных атомов. Иными словами, данная энергия является наиболее вероятной для распыленных атомов.

Выражение (3) показывает, какая доля распыленных атомов испытывает столкновение в процессе транспорта от мишени к подложке при фиксированном давлении и расстоянии между мишенью и подложкой $L$. Наибольший интерес вызывает влияние давления на транспорт распыленных атомов, поэтому необходимо ограничить диапазон величины $L$, в котором будет проводиться дальнейшее рассмотрение. Для этого определим вид зависимости $C(L)$ для расстояний катод-подложка, не превышающих длину свободного пробега. По оси абсцисс отложим

Письма в ЖТФ, 2017, том 43, вып. 17 


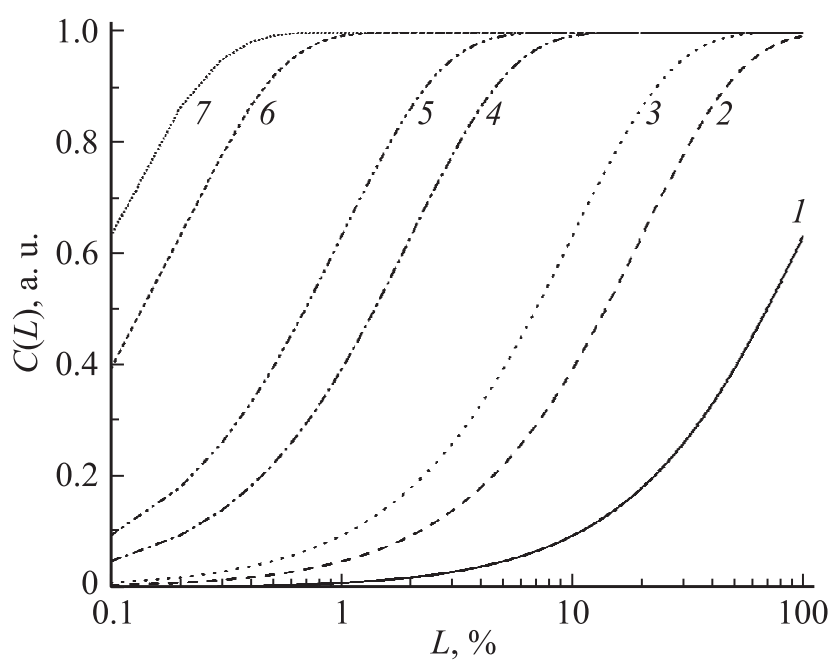

Рис. 1. Доля распыленных атомов, испытавших столкновения при транспорте, в зависимости от расстояния катод-подложка при фиксированных давлениях рабочего газа: $10^{-5}(1), 5 \cdot 10^{-5}(2), 10^{-4}(3), 5 \cdot 10^{-4}(4), 10^{-3}(5), 5 \cdot 10^{-3}(6)$ и $10^{-2}$ Torr (7)

расстояние между катодом и подложкой в процентах, где 100\% соответствуют максимальному значению $\lambda$ в рассматриваемом диапазоне давлений. Для построения взяты давления из диапазона, включающего значения, типичные для современных магнетронных систем, и соответствующие им длины свободного пробега. Полученные зависимости $C(L)$ изображены на рис. 1.

Представленная зависимость демонстрирует, что с ростом расстояния между катодом и подложкой увеличивается доля атомов, испытавших столкновения. Кроме того, видно, что с увеличением давления газа доля столкнувшихся атомов также растет. На основе данных зависимостей условимся проводить дальнейшие расчеты для расстояний между катодом и подложкой в пределах $1 \%$ от максимальной длины свободного пробега: для давлений более $5 \cdot 10^{-3}$ Torr при превышении данного расстояния $C(L)$ стремится к единице.

Возвращаясь к (1) и учитывая (2-4), мы получили выражение для расчета количества распыленных атомов $N_{f}\left(P_{g}\right)$, не испытавших

6 Письма в ЖТФ, 2017, том 43, вып. 17 


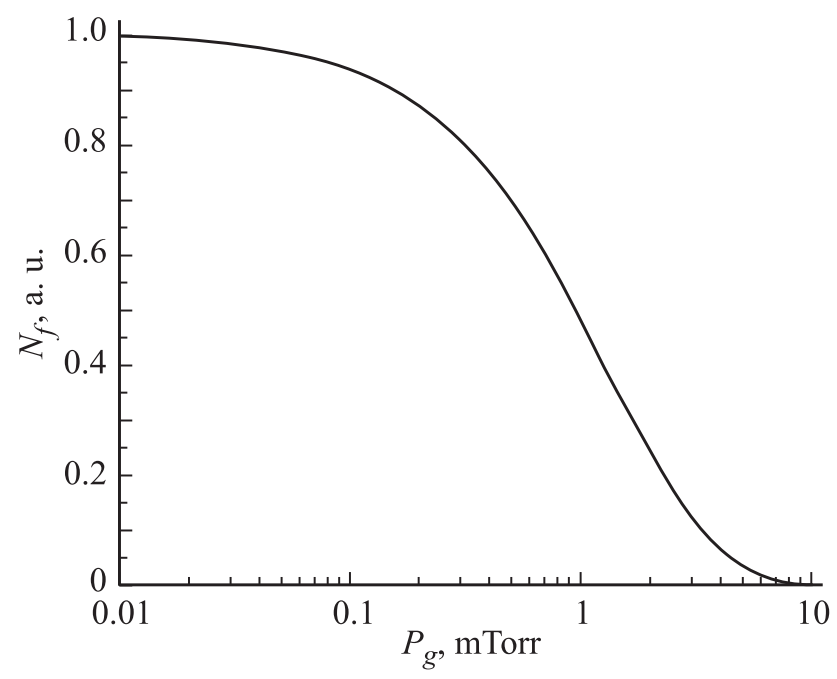

Рис. 2. Доля нерассеянных распыленных атомов в зависимости от давления рабочего газа.

соударений на длине $L$ :

$$
N_{f}=\frac{I K\left(E_{0}\right)}{e} \exp \left(-\frac{\sqrt{2} P_{g} \sigma L}{k_{\mathrm{B}} T}\right) .
$$

Приведенная на рис. 2 зависимость $N_{f}\left(P_{g}\right)$ показывает, что с ростом давления происходит уменьшение доли распыленных атомов, которые не испытывают рассеяния на расстоянии катод-подложка. Вид зависимости обусловлен, с одной стороны, уменьшением длины свободного пробега распыленного атома с ростом давления, а с другой уменьшением коэффициента распыления.

Полученная зависимость требует экспериментальной проверки. Эксперименты проводились на вакуумной напылительной установке Nexdep (Angstrom Engineering, Canada) с двухступенчатой безмасляной системой откачки. Установка оснащена планарным магнетроном ONYX 3 (Angstrom Science, USA) с дисковым кремниевым катодом диаметром $76.2 \mathrm{~mm}$ (Гирмет, Россия), а также источником питания EQ1R1200 (Glassman High Voltage, USA), работающим в режиме постоянного тока. 


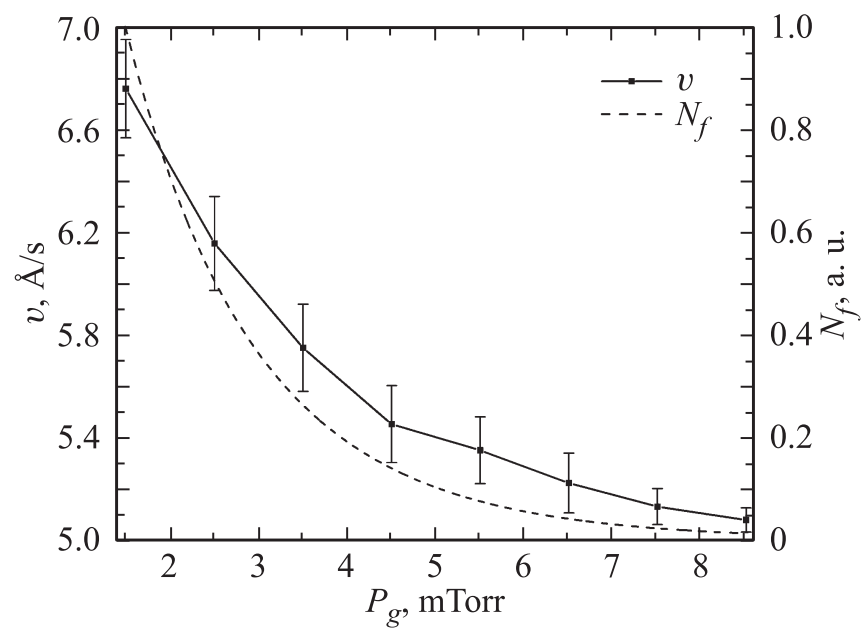

Рис. 3. Зависимость скорости роста и доли нерассеянных распыленных атомов от давления рабочего газа.

В качестве рабочего газа был использован аргон. Контроль толщины полученных пленок осуществлялся с помощью пьезокварцевого датчика Inficon SQM-242 (Sigma Instruments, USA). В рамках работы была получена серия из восьми пленок кремния толщиной $200 \mathrm{~nm}$ на подложках из стекла в диапазоне давлений $1.5-8.5$ mTorr с шагом $1 \mathrm{mTorr}$. $\mathrm{B}$ процессе напыления подложки нагревались до $150^{\circ} \mathrm{C}$. Скорость роста пленок $v$ фиксировалась в процессе напыления.

Из общих соображений ясно, что скорость роста пленки непосредственно связана с количеством достигших подложки атомов. Простая оценка, основанная на модели упругих соударений, показывает, что атом кремния при столкновении с атомом аргона теряет порядка $97 \%$ своей энергии. Очевидно, что больший вклад в процесс роста пленки вносят атомы кремния, не испытавшие столкновений. Поэтому представляется допустимым сравнивать скорость роста пленки с долей нерассеянных распыленных атомов.

Экспериментально полученная зависимость скорости роста пленок кремния от давления обнаруживает корреляцию с теоретически рассчитанной зависимостью доли нерассеянных распыленных атомов (рис. 3).

6* Письма в ЖТФ, 2017, том 43, вып. 17 
Из экспериментальной зависимости видно, что скорость роста пленки убывает с увеличением давления рабочего газа. Таким образом, можно говорить о том, что расчеты, проведенные с помощью описанной выше модели, подтверждаются экспериментальными данными.

Следует отметить, что модель предсказывает более резкую зависимость доли рассеянных атомов от давления, чем наблюдается для экспериментально определенной скорости роста. Причиной этого может быть то, что в модели не учитывалось угловое распределение распыленных атомов [8]. Отметим также, что не все достигшие подложки атомы участвуют в формировании пленки, некоторая часть реиспаряется. Учет углового распределения распыленных атомов, а также более детальное рассмотрение процесса зародышеобразования и роста пленки будут проведены в дальнейших работах.

Проведенные теоретические расчеты и экспериментальные исследования показали, что рассеяние распыленных атомов оказывает существенное влияние на скорость роста пленок, полученных магнетронным распылением. При увеличении давления в рассматриваемом диапазоне 1.5-8.5 mTorr скорость роста пленок кремния изменяется на $25 \%$, при этом уменьшение доли нерассеянных распыленных атомов на расстоянии катод-подложка достигает 90\%. Таким образом, оптимизация конструкции с учетом влияния рассеяния распыленных атомов и получение пленок при более низких давлениях могут повысить производительность МРС. Следует отметить, что изменение условий транспорта распыленных атомов представляется основной причиной изменения свойств пленок, экспериментально обнаруженного авторами ранее $[9,10]$.

Исследование выполнено при частичной финансовой поддержке РФФИ в рамках грантов 16-07-00226 А и 16-08-00524 А.

\section{Список литературы}

[1] Пресняков М.Ю., Сладкопевиев Б.В., Белоногов Е.К. // Письма в ЖТФ. 2016. T. 42. B. 23. C. $58-65$.

[2] Соловьев А.А., Сочугов Н.С., Оскомов К.В., Работкин С.В. // Физика плазмы. 2009. Т. 35. № 5. С. 443-452.

[3] Рогов А.В., Капустин Ю.В., Мартыненко Ю.В. // ЖТФ. 2015. Т. 85. В. 2. C. $126-134$. 
[4] Volpyas V.A., Komlev A.Y., Platonov R.A., Kozyrev A.B. // Phys. Lett. A. 2014. V. 378. Iss. 43. P. 3182-3184.

[5] Shon C.H., Lee J.K. // Appl. Surf. Sci. 2002. V. 192. Iss. 1-4. P. 258-269.

[6] Шешин Е.П. Вакуумные технологии: учебное пособие. Долгопрудный: Интеллект, 2009. 504 с.

[7] Thompson M.W. // Vacuum. 2002. V. 66. Iss. 2. P. 99-114.

[8] Корнющенко А.С., Перекрестов В.И., Наталич В.В., Загайко И.В. // Письма в ЖТФ. 2017. Т. 43. В. 4. С. 94-101.

[9] Митин Д.М., Сердобинцев А.А. // ФТП. 2013. Т. 47. В. 9. С. 1276-1278.

[10] Митин Д.М., Александров В.А., Скапцов А.А., Вениг С.Б., Сердобинцев A.A. // Поверхность. Рентгеновские, синхротронные и нейтронные исследования. 2015. № 6. С. 1-4.

Письма в ЖТФ, 2017, том 43, вып. 17 